\title{
O Nascimento do Segundo Filho e as Relações Familiares ${ }^{1}$
}

\author{
Cesar Augusto Piccinini ${ }^{2}$ \\ Caroline Rubin Rossato Pereira \\ Angela Helena Marin \\ Rita de Cássia Sobreira Lopes \\ Universidade Federal do Rio Grande do Sul \\ Jonathan Tudge \\ University of North Carolina at Greensboro
}

\begin{abstract}
RESUMO - O nascimento do segundo filho pode gerar um aumento na tensão familiar, pois traz a necessidade de reformulações nos papéis e regras do funcionamento familiar. O presente estudo investigou o impacto do nascimento do segundo filho nas relações familiares, especialmente quanto às mudanças na rede de apoio, relação conjugal, comportamentos do primogênito e relação genitores-primogênito. Participaram do estudo oito famílias, nas quais o segundo filho havia nascido no segundo ano de vida do primogênito. Os genitores foram entrevistados no $18^{\circ}, 24^{\circ}$ e $36^{\circ}$ mês de vida do primogênito. Análise de conteúdo qualitativa revelou o esforço de cada membro das famílias para lidar com as ambigüidades dessa situação, pois ao mesmo tempo que o segundo filho é celebrado, ele também altera uma dinâmica familiar relativamente estável envolvendo a tríade pai-mãe-primogênito. Embora as mudanças tenham sido acompanhadas de ansiedade e instabilidade nas relações, os resultados destacam a capacidade adaptativa dos membros dessas famílias.
\end{abstract}

Palavras-chave: primogênito; segundo filho; relações familiares; família.

\section{The Second Child's Birth and Family Relations}

\begin{abstract}
The second child's birth can increase family tension because it brings a need for reformulation of its roles and functioning rules. The aim of this study was to investigate the impact of the second child's birth on family relations, with special attention to the changes in social support, marital relationship, firstborn's behaviors and parents-first born relationship. Eight families, in which the second child had been born during the first born's second year of life, participated in the study. The parents were interviewed during the first born's 18th, 24th and 36th month. The qualitative content analysis revealed the effort of each family member to deal with the ambiguities of this situation which, at the same time the second child is celebrated, changes a relatively steady familiar dynamics involving the father-mother-first-born triad. Although the changes brought anxiety and instability to family relations, the results highlight the adaptiveness of the members of these families.
\end{abstract}

Key words: firstborn; second child; family relations; family.

A chegada de um novo membro à família pode gerar um aumento na tensão familiar, pois traz consigo a necessidade de uma reformulação nos papéis de cada um de seus membros e nas suas regras de funcionamento (Minuchin, 1985). Em particular, o nascimento do segundo filho constitui um momento marcante no desenvolvimento da família (Dessen, 1997; Pereira \& Piccinini, no prelo) e pode ser considerado como um acontecimento nodal no ciclo de vida familiar. Carter e McGoldrick (1989/2001) definem acontecimentos nodais como os eventos capazes de criar instabilidade no funcionamento do sistema familiar. Momentos de transição como este, são tipicamente associados ao aumento no estresse, pois afetam a dinâmica familiar (Minuchin, 1985). Assim sendo, cada membro da família (pai, mãe e primogênito) e, em especial, suas relações (relação conjugal, relação genitores-primogênito e o incipiente relacionamento

1 Gostaríamos de agradecer ao CNPq e a Spencer Foundation (financiamento ao último autor) pelo auxílio financeiro recebido.

2 Endereço: Rua Ramiro Barcelos 2600/111, Porto Alegre, RS, Brasil 90035-003.E-mail: piccinini@portoweb.com.br fraterno) poderão ser afetadas de modo distinto (Dessen, 1997; Silveira, 2002).

Ao se estudar a adaptação familiar ao nascimento do segundo filho é preciso considerar também a influência de fatores que extrapolam o sistema familiar nuclear, como a rede de apoio, que pode funcionar como recurso importante, uma vez que ajuda a família em sua adaptação e na manutenção de seu equilíbrio (Dessen, 1997; Feiring \& Lewis, 1978; Kreppner, Paulsen \& Schuetze, 1982). A pesquisa de Dessen e Braz (2000), por exemplo, investigou a rede de apoio no momento do nascimento dos filhos em famílias brasileiras que possuíam entre um e quatro filhos e revelou que a grande maioria das mães relatou mudanças antes e após o evento, sendo estas consideradas, especialmente, como positivas. Dentre estas alterações, referiram: apoio psicológico; cuidados físicos; orientações sobre alimentação, gravidez e filhos; ajuda financeira; ajuda nas tarefas domésticas e no cuidado dos filhos. As principais fontes de apoio mencionadas foram os familiares, seguidos pelos não-familiares (amigos, vizinhos, babá/empregada), profissionais da saúde (médicos) e instituiçõos (centros de saúde). Destacou-se o 


\section{A. Piccinini e cols}

papel da avó materna, o qual foi apontado pelas mães como o mais significativos após o companheiro.

$\mathrm{Na}$ literatura, parece haver um consenso de que a relação conjugal constitui a principal fonte de apoio à mulher no período do nascimento de um filho (Belsky, 1981). Na pesquisa realizada por Dessen e Braz (2000), todas as mães destacaram o companheiro como a figura mais importante na provisão de apoio durante a gestação e nos primeiros meses de vida do bebê. Relataram, também, dentre as mudanças positivas percebidas neste período, uma melhoria na relação conjugal. Contudo, ao se examinar o apoio fornecido pelo companheiro da gestante no contexto do nascimento do segundo filho é importante que se explicitem os diferentes papéis assumidos pelo homem junto ao grupo familiar, o que inclui, além do papel conjugal, o papel parental (relação paifilho). Considerando estes dois papéis, Levitt, Weber e Clark (1986), em um estudo realizado com mães norte-americanas grávidas do primeiro ou do segundo filho, demonstraram que, de modo geral, o bem-estar materno no período pósparto estava vinculado tanto à qualidade da relação conjugal, quanto ao montante de apoio recebido do companheiro no que se referia às tarefas domésticas e ao cuidado dos filhos. Com isso, a complementaridade de papéis parentais parece se fazer fundamental na busca de uma nova adaptação familiar neste momento.

Mesmo que o apoio do companheiro seja apontado como essencial no momento do nascimento dos filhos, observa-se que as mudanças associadas a este evento podem não ser facilmente conduzidas pelo casal. A sobrecarga de trabalho devida aos cuidados do bebê, a atenção demandada pelos filhos, bem como a divisão de tarefas domésticas, precisam ser redefinidas, especialmente se ambos os pais trabalham fora (Carter \& McGoldrick, 1989/2001; Dessen, 1997; Dessen \& Braz, 2000). Para Carter e McGoldrick (1989/2001), esta necessidade de negociação de tarefas e trabalhos aparece como o principal gerador de conflito entre os casais com crianças pequenas. Além disso, o pouco tempo a sós, as constantes demandas dos filhos e o excesso de preocupação dos pais, podem ameaçar os momentos de intimidade do casal. Com o nascimento do segundo filho, essa situação pode se agravar, reforçando os papéis parentais e levando a um maior distanciamento do casal (Bourguignon \& cols., 1980).

No desenvolvimento da família, o nascimento do segundo filho caracteriza a fase de expansão do sistema e é considerado qualitativamente diferente do processo do nascimento do primeiro filho (Dessen, 1997; Gottlieb \& Baillies, 1995). O casal, que já havia assumido o papel parental quando do nascimento do primeiro filho, precisa, agora, diferenciálo e especificá-lo de acordo com cada uma das crianças, assumindo o papel de pais de dois filhos. Além do casal, o primogênito também está envolvido neste processo e tem de lidar com a nova situação e passar do papel de filho único para o de irmão mais velho (Walz \& Rich, 1983).

O nascimento de um irmão exerce um impacto direto na vida do primogênito, pois ocorrem grandes mudanças no seu ambiente social (Kowaleski-Jones \& Dunifon, 2004). Ele passa a conviver com um novo indivíduo que se apresenta pouco preparado para interagir com ele e sua relação com os genitores se altera de modo importante (Dunn \& Kendrick, 1986). Dunn e Kendrick (1980, 1986) acompanharam algumas famílias inglesas com um filho (18-43 meses de vida) desde o último trimestre gestacional do segundo filho até 14 meses após seu nascimento e constataram que quase todos os primogênitos observados mostraram sinais de descontentamento. De acordo com o relato das mães, após o nascimento do irmão, a grande maioria dos primogênitos passou a apresentar mais condutas caprichosas e travessuras, aumento na dependência e na propensão ao choro e comportamentos imitativos do bebê (fala infantilizada, pedido de colo, retrocesso na aprendizagem de hábitos de toalete). Além disso, alguns primogênitos apresentaram aumento da introversão e problemas relacionados ao sono. Entretanto, estes comportamentos eram também acompanhados de demonstrações de carinho e interesse pelo bebê. Esta resposta ambivalente do primogênito frente ao nascimento de um irmão foi corroborada pelos estudos de Field e Reite (1984) e Stewart, Mobley, Van-Tuyl e Salvador (1987), ambos realizados com famílias norte-americanas.

No que se refere à realidade brasileira, o estudo de caso relatado por Dessen e Mettel (1984), realizado com uma família de classe média, antes e após o nascimento do seu segundo filho, apontou aspectos semelhantes aos relatados acima. Embora o primogênito (com idade de 2 anos e meio) parecesse aceitar bem o irmão, emitindo comportamentos de carinho e de ajuda nos cuidados do bebê, apresentou, concomitantemente, um aumento nas exigências em direção à mãe, aumento na agressividade em direção ao pai e problemas de sono e de toalete.

Apesar do grande impacto relatado quando do nascimento de um irmão, Kreppner e cols. (1982) destacaram que a maioria dos primogênitos tende a apresentar um gradual retorno aos padrões anteriores de funcionamento. Para os autores, este período se faz necessário para que se estabeleçam novas identificações, papéis e funções familiares adequados ao novo contexto.

A chegada de um novo bebê, além de afetar o comportamento do primogênito, também pode levar a mudanças na relação dos genitores com o primeiro filho. Estas mudanças podem ocorrer tanto em um nível comportamental (qualidade, frequiência e padrões relativos de interação) quanto em um nível mais abstrato, incluindo as percepções e emoções dos envolvidos. A freqüência e a qualidade afetiva das interações e o estilo disciplinar dos genitores são alguns aspectos afetados durante esta transição, os quais podem estar mediando a reação do primogênito ao nascimento do irmão (Baydar, Greek \& Brooks-Gunn, 1997). A este respeito, Stewart e cols. (1987) afirmaram que as mudanças no comportamento do primogênito atuam como estratégias para reaver as interações e a atenção desfrutada até o momento anterior ao nascimento do irmão.

Dentre as relações genitores-primogênito, o principal impacto da gestação e do nascimento do segundo filho parece ser sentido no relacionamento com a mãe, uma vez que alterações devido à gravidez, o afastamento para a hospitalização, e, de modo marcante e prolongado, as demandas do recém-nascido desorganizam esta relação. Conforme relatado em diversos estudos (Dunn \& Kendrick, 1980, 1986; Field \& Reite, 1984; Stewart \& cols., 1987), após a chegada do segundo filho, parece haver uma diminuição acentuada nas interações mãe-primogênito, na atenção materna e no tempo que ocupavam em brincadeiras e 
Tabela 1. Dados demográficos dos participantes.

\begin{tabular}{|c|c|c|c|c|c|c|c|c|}
\hline Caso & $\begin{array}{l}\text { Idade } \\
\text { Mãe }\end{array}$ & $\begin{array}{l}\text { Escolarid. } \\
\text { Mãe }\end{array}$ & $\begin{array}{l}\text { Ocupação } \\
\text { Mãe }\end{array}$ & $\begin{array}{c}\text { Idade } \\
\text { Pai }\end{array}$ & $\begin{array}{c}\text { Escolarid. } \\
\text { Pai }\end{array}$ & $\begin{array}{c}\text { Ocupação } \\
\text { Pai }\end{array}$ & $\begin{array}{c}\text { Idade } \\
\text { Primog. }\end{array}$ & $\mathrm{NSE}^{*}$ \\
\hline 01 & 37 & méd.comp. & secretária & 38 & fund.incomp & mecânico & $22 m$ & 3 \\
\hline 02 & 33 & sup.comp. & dentista & 38 & pós-grad. & dentista & $24 \mathrm{~m}$ & 5 \\
\hline 03 & 26 & sup.incomp. & do lar & 32 & sup.comp. & professor & $18 \mathrm{~m}$ & 3 \\
\hline 04 & 17 & méd.incomp & do lar & 19 & méd. comp. & auto-peças & $17 \mathrm{~m}$ & 2 \\
\hline 05 & 33 & sup.comp. & fonaudióloga & 33 & sup.comp. & designer & $34 \mathrm{~m}$ & 5 \\
\hline 06 & 37 & sup.comp. & pedagoga & 38 & sup.incomp. & construtor & $24 \mathrm{~m}$ & 4 \\
\hline 07 & 18 & méd.incomp & estudante & 19 & méd.incomp. & repositor & $15 \mathrm{~m}$ & 5 \\
\hline 08 & 24 & méd.incomp & do lar & 22 & méd.comp & militar & $16 \mathrm{~m}$ & 2 \\
\hline
\end{tabular}

Nota. Classificação de Hollignshead (1975): 1(baixo); 2 (médio-baixo); 3 (médio); 4 (médio-alto) e 5 (alto).

jogos conjuntos. Ao mesmo tempo, Dunn e Kendrick (1980, 1986) perceberam um aumento na incidência de enfrentamentos mãe-primogênito e de proibições e repreensões maternas, bem como uma diminuição da iniciativa materna em interações positivas com o primogênito, de modo que este passou a assumir relativamente maior responsabilidade pela iniciação de conversação e brincadeira com a mãe. Assim, segundo Brazelton e Sparrow (2003), quando a mãe se volta para seu novo bebê, ela afasta-se imperceptivelmente do primogênito.

Conforme exposto, o nascimento de um segundo filho traz consigo a necessidade de adaptações constantes por parte de toda a família, constituindo-se em um evento potencial para mudanças em cada um dos membros familiares e em suas relações intrafamiliares, bem como naquelas estabelecidas com o entorno social. Assim, o presente estudo teve por objetivo descrever o impacto do nascimento do segundo filho na dinâmica das relações familiares, particularmente na rede de apoio, na relação conjugal, nos comportamentos do primogênito e na relação genitores-primogênito.

\section{Método}

\section{Participantes}

Participaram deste estudo oito famílias constituídas pelo mãe, pelo pai e seus dois filhos. Todas as famílias faziam parte do Estudo Longitudinal de Porto Alegre: da Gestação à Escola (Piccinini, Tudge, Lopes \& Sperb, 1998), que teve por objetivo investigar tanto os aspectos subjetivos e comportamentais das interações iniciais pai-mãe-bebê, como o impacto de fatores iniciais do desenvolvimento nas interações familiares, no comportamento social de crianças pré-escolares e na transição para a escola de ensino fundamental. O estudo iniciou acompanhando 81 gestantes da cidade de Porto Alegre (RS), que não apresentavam intercorrências clínicas com elas mesmas ou com o bebê, que era seu primeiro filho. Os maridos $^{3}$, caso residissem juntos em situação matrimonial, também foram convidados a participar do estudo. Os participantes representavam diferentes configurações familiares (nucleares, monoparentais ou recasados), de diferentes idades (adultos e adolescentes) e com escolaridade e níveis socioeco-

3 No presente estudo, as palavras marido e esposa são utilizadas para representar tanto situações matrimoniais oficiais como aquelas envolvendo casais que eram coabitantes. nômicos variados. Foram realizadas várias coletas de dados, desde a gestação até os 7 anos das crianças (gestação, 3ㅜㅜ 8ㅜ, $12^{\circ}, 18^{\circ}, 24^{\circ}, 30^{\circ}$ meses e $6^{\circ}$ e e 7 o ano de vida da criança). O estudo foi aprovado pelo Comitê de Ética da Universidade Federal do Rio Grande do Sul (UFRGS).

Para o presente estudo foram selecionadas todas as famílias nas quais havia nascido um segundo filho quando o primogênito estava no segundo ano de vida. Dentre as oito famílias investigadas, em seis casos a díade fraterna era mista (quatro com primogênitos do sexo feminino e dois com primogênitos do sexo masculino) e em dois casos era constituída de irmãos do mesmo sexo (uma díade feminina e a outra masculina). A Tabela 1 apresenta as características demográficas das famílias.

\section{Delineamento, procedimentos e instrumentos}

Utilizou-se um delineamento de estudos de casos coletivos (Stake, 1994) para investigar o impacto do nascimento do segundo filho na dinâmica das relações familiares. Em particular, investigaram-se as mudanças percebidas pela mãe e pelo pai no que se refere à rede de apoio, à relação conjugal, aos comportamentos do primogênito e à relação genitores-primogênito.

Embora as famílias participantes do estudo longitudinal (Piccinini \& cols., 1998) tenham sido acompanhadas desde o terceiro trimestre de gestação do primeiro filho, os dados a respeito do nascimento do segundo filho começaram a ser coletados somente a partir do $18^{\circ}$ mês de vida do primogênito, de modo que, para este estudo, foram utilizados dados das entrevistas realizadas com os genitores no $18^{\circ}, 24^{\circ}$ e $30^{\circ}$ mês de vida do primeiro filho. Nestas fases de coleta de dados, foram utilizados diversos instrumentos, conforme detalhado em Piccinini e cols. (1998). Destacam-se aqui apenas os instrumentos respondidos pelas mães e pais, cujos dados foram utilizados no presente estudo, a saber: Entrevista de Dados Demográficos (GIDEP, 1998), realizada com a gestante no terceiro trimestre da gestação para investigar as características sócio-demográficas das famílias; Entrevista do Casal aos 18 meses (GIDEP, 2000a), realizada conjuntamente com o casal quando o primogênito estava com 18 meses, visando obter informações referentes à relação conjugal (i.e relacionamento conjugal; modelo de casal; relacionamento conjugal dos pais dos genitores); Entrevista sobre Práticas Educativas Parentais (GIDEP, 2000b), realizada separadamente com cada um dos genitores no $18^{\circ}$ e no $24^{\circ}$ 
mês de vida do primogênito, com o objetivo de investigar aspectos referentes às práticas educativas utilizadas pelos genitores com o primogênito (i.e. hora das refeições; afastamento da criança; troca de roupa; hora de ir para a cama; hora do banho; birra); Entrevista sobre a Experiência da Maternidade e o Desenvolvimento da Criança (GIDEP, 2000c) e Entrevista sobre a Experiência da Paternidade e o Desenvolvimento da Criança (GIDEP, 2000d), realizadas, respectivamente, com a mãe e com o pai no $18^{\circ}$ e no $24^{\circ}$ mês de vida do primogênito, que investigaram aspectos da experiência da maternidade/paternidade e do desenvolvimento do primogênito (i.e. experiência como pai/mãe: dificuldades, autopercepção; percepção do cônjuge como pai/mãe; momentos de afastamento da criança; habilidades da criança, linguagem, controle esfincteriano, brincadeiras, objeto preferido); Entrevista com os Pais aos 30 meses (GIDEP, 2001), realizada com a mãe e o pai para verificar eventuais mudanças ocorridas na vida do primogênito desde o seu $24^{\circ}$ mês de vida (i.e. desenvolvimento/crescimento da criança; problemas de saúde; acontecimentos especiais; preocupações dos pais com relação à criança). Dentre os dados coletados por meio destes instrumentos, para o presente estudo, foram analisados apenas aqueles relatos referentes a mudanças percebidas pelos genitores como vinculadas ao nascimento do segundo filho.

\section{Resultados}

A análise de conteúdo qualitativa (Bardin, 1977; Laville \& Dionne, 1999) foi utilizada para investigar o impacto do nascimento do segundo filho na dinâmica das relações familiares. Esta temática foi examinada com base em quatro categorias: rede de apoio; relação conjugal; comportamentos do primogênito; e relação pais-primogênito, derivadas da literatura (Baydar \& cols., 1997; Dessen \& Braz, 2000; Gottlieb \& Baillies, 1995; Stewart \& cols., 1987) e das entrevistas realizadas Dois dos autores do presente artigo classificaram separadamente os relatos dos genitores em cada uma das categorias, recorrendo-se a um terceiro colega em caso de discordância. A seguir, apresenta-se a descrição das categorias ilustradas pelos relatos dos participantes.

\section{Rede de apoio}

Após o nascimento do segundo filho, as participantes relataram mudanças na rede de apoio, recebendo destaque as três seguintes fontes: a família extensa, o companheiro, e a creche do primogênito. Dentre estas, o apoio da família extensa e do companheiro foram os mais enfatizados.

O apoio recebido das famílias extensas foi salientado pelas mães, ressaltando-se o auxílio oferecido no cuidado dos filhos: "Com alguma freqüência a gente diz: Ah! Vamos largar lá na avó pras crianças passarem uma noite lá, pra gente poder sair ou fazer alguma coisa assim" (M2-30m $)^{4}$. Além disso, as mães destacaram o maior envolvimento da

4 A letra e o número entre parênteses identificam o participante que forneceu o relato (M: mãe; P: pai) e a idade do filho primogênito no momento da entrevista. avó materna: "É difícil agora com os dois pra conciliar. Se não fosse pela mãe [avó materna] me ajudando. Ela ajuda um monte, fica lá em casa o dia inteiro. [...] Ela [avó paterna] ajuda sim, sempre vem aqui em casa, mas mais é a mãe [avó materna] que fica o dia inteiro" (M4-24m); "De vir ajudar, oferecer ajuda, estar disponível. O tempo todo que eu passei dentro do hospital [para o parto] minha mãe que ficava comigo. Claro, não era a filha dela que tava lá [Referindo-se à sogra]. Minha mãe vinha aqui, ela limpava as coisas, ela dizia que o L. [companheiro] passou o tempo todo também sem comer, nervoso. Ela ia ao super fazia as compras e deixava pro L. comer. Se preocupou com o filho que não é dela, enquanto a mãe dele não se preocupou” (M8-18m). Um pai também salientou o envolvimento da família extensa: "Todos os avós também se envolvem na disciplina dela [primogênita] quando estão presentes" (P3-30m).

Com relação ao apoio recebido do companheiro, as mães destacaram sua satisfação pela participação destes nos cuidados diários dos filhos: "Eu acho que ele [companheiro] é um bom pai. Ele tem a qualidade de se dedicar. Ele lê livro, ele procura livro pra eles, ele conta histórias. Então, nós temos uma combinação: ele conta história, eu não conto história. [...] Ele chega, senta no chão, dá comida, janta pra eles, de noite, quando eu vou pra aula" (M3-36m); "O L. [companheiro] sempre fez tudo. Ele dá banho nela [primogênita], ele troca. E quando ele não tá em casa eu cuido da E. [primogênita]. [...] Ele faz tudo, tudo. Ele ajuda, ele toma iniciativa. A primeira mamadeira da manhã quem faz é ele" (M8-18m); e nas brincadeiras com o primogênito: "Ele [companheiro] brinca muito com $o$ A. [primogênito], também dá mais atenção pra ele. E ele [companheiro] brinca muito com ele [primogênito]" (M4$18 \mathrm{~m})$. Um pai também salientou seu envolvimento com os filhos: "Dividimos as tarefas na criação deles. Salvo o parir e o amamentar, eu me sinto completamente envolvido em todo processo de criação deles [filhos]" (P6-30m).

No que se refere às instituições de apoio, as mães destacaram a importância da creche do primogênito como recurso para o cuidado dele no período após o nascimento do segundo filho: "Eu coloquei a $D$. [primogênita] na creche por causa da $F$. [segunda filha], porque eu achava que eu trabalhando em casa não ia conseguir dar conta de cuidar das duas, como eu realmente não consigo cuidar de uma só" (M8-24m). Antecipando o impacto do nascimento do segundo filho, as mães referiram sua preocupação em colocar o primogênito na creche com certa antecedência, como forma de preparação: “Dois meses antes de o F. [segundo filho] nascer, mais ou menos, nós colocamos ela na escolinha” (M2-30m); "Eu queria levar ela [primogênita] para a creche por causa da $F$. [segunda filha], ela tem ciúmes. Como ela [primogênita] entrou direto no berçário, ela ia ter mais contato com criancinhas bebezinhas. Foi por esse motivo e também porque, de repente, quando eu ganhasse a $F$. [segunda filha] ela estaria na creche e não ia sentir tanto aquele impacto de ficar longe de mim" (M8-24m). Um pai também manifestou esta preocupação: "Eu já tô pensando em procurar uma creche pra ela começar a se adaptar. Pra não ficar muito em cima quando nascer o nenê e afastar ela. Acho que vai se adaptar melhor" (P1-18m). 


\section{Relação conjugal}

Tanto as mães quanto os pais referiram mudanças na relação conjugal após o nascimento do segundo filho. As mães destacaram o grande envolvimento com o cuidado dos filhos e o pouco tempo para o casal: "Como eu te disse, a gente [casal] é todo o tempo sempre criança. A gente meio que se esqueceu esse tempo todo. Então, a gente, de vez em quando, resgata assim: 'E nós? E aí? E nós?' E a gente tenta refazer esse tipo de resgate. Só que a gente não tem um espaço para a gente. Ainda não conseguiu ter um espaço. Com certeza, eu acho que não tem nem dúvida, isso fica em segundo, terceiro, quarto, quinto, sexto plano. Eles são eles" (M6-30m); "Nosso relacionamento [casal] tá bom. Claro que não é do mesmo jeito de quando a gente não tinha filhos, era tudo en e o L. [companheiro]. Agora, cada dia que passa, tem uma coisa diferente acontecendo. Acontece uma coisa diferente ou falta tal coisa, aí eu falo para ele e a gente meio que discute" (M8-18m). Os pais confirmaram esta tendência: "Ah тиdou [o relacionamento do casal]. Muda porque a gente já tem menos tempo, quando um [filho] pára, o outro resolve chamar atenção. É assim, se tu tá envolvido com um, daqui a pouco tá com os dois, daqui a pouco tu não tá com nenhum, tu tá morto. O envolvimento é grande" (P5-30m); "Acho que a única mudança [no relacionamento do casal] é que quando entra os dias no meio a gente se afasta um pouco. A gente quando é namorado toda hora tá grudado, mas quando entram os filhos e entram as responsabilidades de casa, aí a gente se afasta um pouco, mas isso é normal. Fica mais em função dos filhos toda hora. Às vezes a gente até pensa: 'Vamos sair?' Aí quando vê: 'Ah, mas o L. [primogênito] tá assim, $o V$. [segundo filho] tá assado. Ah, não, não vamos.'” (P7-24m); "Tempo agora a gente [casal] não tá tendo muito, a gente procura dar atenção pras duas [filhas]. Vamos procurar deixar a $F$. [segunda filha] um pouquinho maior, que agora ela tá chorando bastante, mamando, aí não dá" (P8-18m).

Estas mudanças foram percebidas, em sua maioria, como tendo um efeito negativo sobre a relação conjugal, aspecto destacado pelas mães: "Tá difícil [relacionamento do casal]. Quando a gente consegue parar e sentar pra conversar a $F$. [segunda filha] chora. Daí a gente busca a F. pra ficar com a gente. E quando a gente quer um momento pra gente vai sempre ter aquela coisa: a E. [primogênita] tá chorando ou a E. tá sonhando e a F. [segunda filha] tá chorando. Mas é isso aí, a gente sabia que era assim" (M8-18m); "Ultimamente tem sido muito difícil. Esses dias a gente foi sair só nós dois pra ir comprar fralda pro L. [segundo filho]. Aí eu disse: ' $E$. [companheiro], quantos anos faz que a gente não sai junto?' Ele ficou... Eu disse: 'faz dois anos'; e ele: 'Capaz!', Eu disse: 'É, faz dois anos que a gente não sai junto. Só nós dois.' Mesmo pra caminhar, que a gente vivia na rua. Faz tempo que ele tá me conversando pra me levar no cinema e não me leva nunca" (M7-24m); e por um pai: "Aí eu acho que tá complicado [relacionamento do casal]. Eu acho que tem que conversar muito, entendeu. E tem que acreditar nisso tudo. Acho que afeta muito o relacionamento do casal [ter mais um filho]" (P6-30m). Frente a estas dificuldades, uma mãe enfatizou a adaptação do casal e a necessidade de preservar um espaço para a relação conjugal: "Eu acho pelo menos que nós [casal] estamos sabendo contornar isso. Isso faz parte. A gente não pode deixar nossos filhos de lado. Claro que a gente não pode esquecer que a gente tem que ter nosso tempo. Tem que arranjar um tempo pra gente, mas sempre quando pode a gente arranja" (M8-18m).

Em oposição à maioria dos relatos, uma mãe percebeu o nascimento do segundo filho como oportunidade para uma melhora na relação conjugal, favorecendo a aproximação do casal: "Tá normal, tá bem tranqüilo. Nós estamos mais parceiros agora do que antes, porque nós dois sozinhos fazíamos as coisas, mas cada um ficava do seu lado e agora não porque ele tem que participar. Então a gente tá sempre em função deles, mas assim: 'Ah, vamos fazer isso, vamos fazer aquilo'. Nós dois estamos, conversando mais. Aí, quando eles dormem, nós vamos pra cozinha tomar uma cervejinha, aí ficamos conversando. Parece que a gente tá arrumando mais tempo agora até pra nós do que antes" (M1-30m).

\section{Comportamentos do primogênito}

Todas as mães e um pai relataram alguma alteração no comportamento do primogênito associada ao nascimento do irmão. As mudanças envolveram sintomas físicos: "Agora tá tranqüilo, mas na época [do nascimento do irmão] ela ficou doente, ficou com febre, ficou muda. Ficava pelos cantinhos, bem jururu, como quem diz: 'Ah, agora tô de escanteio'. Mas depois foi passando" (M1-30m); "Quando eu ganhei a F. [segunda filha] foi quando ela [primogênita] adoeceu. Ela entrou em depressão. Ficou praticamente dez dias sem beber nada. [...] Esse problema da alergia apareceu no dia que a $F$. [segunda filha] nasceu. O corpo dela [primogênita] fechou todinho com alergia" (M8-24m); mudanças na linguagem: "A gente foi elaborando com ela [primogênita], eu acho que foi bem interessante, mas ela ficou gaga. A gente atribuiu a gagueira ao nenê [segundo filho]" (M5-30m); "Ele [primogênito] começou a falar com um ano e meio. Então, eu acho que a linguagem dele tá super avançada, mas em alguns momentos ele regride, até em função da mana [segundo filho]. Ele fala com ela como um bebê, ele se dirige a ela como um bebê. Eu acho que ele tá infantilizando a fala dele. Eu vejo ele dando uns puxões para trás nessa coisa de falar" (M6-30m); retrocessos na alimentação: "Antes ele [primogênito] queria comer sozinho, agora, como $o \mathrm{~V}$. [segundo filho] está comendo, ele também quer que eu dê pra ele. Eu tenho que dar pro V. e pra ele" (M7-24m); "Muita coisa mudou no comportamento dela [primogênita]. Ela tomar a mamadeira é uma das coisinhas poucas que começou a mudar. Muito choro, muita manha. Às vezes ela queria o colo pra ela" (M2-30m); propensão ao choro: "Tá numa fase. Também não sei se ela [primogênita] tá assim por causa do bebê. Qualquer coisa que tu fala pra ela, ela chora. É super sentimental. Tu fala as coisas pra ela e ela chora, mas não aquele choro só de chorar, ela chora de ficar sentida" (M8-18m); e birra: "Foi essa questão da birra, dele [primogênito] se jogar no chão, de bater pé. Na realidade ele sempre teve um comportamento super moldável. Agora que isso tá presente em função da idade, em função de que agora a mana tá muito engraçadinha e todas as atenções são pra ela. Então, de repente ele dá uma guinada. Embora ele goste muito dela, ele tá sempre junto com ela, mas ele dá 
uma guinada. Foi uma criança super calma, super calma, na dele. Agora que ele tá diferente. Mas senão ele foi sempre uma criança de boa paz," (M6-36m).

Além destas mudanças, as mães referiram algumas demonstrações de agressividade como sinais de ciúmes no primogênito: "Porque às vezes ela [primogênita] tem ciúmes do F. [segundo filho], briga com o F., agressões. Tava mordendo. Ela nunca mordeu na vida dela, agora de repente começou a morder o irmão. Então a gente sabe que é por ciúmes" (M3-36m); "Com o irmão, ele [primogênito] é ciumento, ciumento, ciumento. Até hoje ele implica um monte com $o V$. [segundo filho]" (M7-24m). Este aspecto também foi apontado por um pai: "Ele [primogênito] puxa o cabelo da $S$. [segundo filho], ou ele tá deitado no sofá e ela vai lá e ele empurra ela, coisa assim. Mas é sempre em cima da menina. Acho que é ciúme, competição, sei lá” (P4-36m).

Entretanto, os genitores, principalmente os pais, destacaram a capacidade adaptativa do primogênito, de modo que as mudanças concentraram-se no período próximo ao nascimento do irmão: "Ela ficou mal. No início foi ruim, depois foi melhorando" (P1-30m); "Foi uns três ou quatro meses que eu percebi de ciúmes (P5-30m)”; “Tem um pouco de ciúmes, mas foi bem no início, foi pouquinho, foi ligeirinho. Gosta, gosta [do irmão]. No começo teve um pouquinho de ciúmes, mas passou" (P7-24m); "Ficou enciumado com o nascimento, no começo. Aí nem encostar nele [primogênito] eu podia. Ele ficou ansioso. Mas agora não, ele até ajuda a cuidar" (M4-18m).

\section{Relação genitores-primogênito}

Após o nascimento do segundo filho, os genitores descreveram mudanças no seu relacionamento com o primogênito. A maioria das mães destacou a necessidade de equilibrar a distribuição da atenção entre os filhos: "Aprender a dividir a atenção. Ela [primogênita] sempre chama a atenção pra ela, sempre. E a gente percebeu. Mas agora ela tem que entender, tem que dividir, ela tem que esperar e isso pra ela é bem difícil. Esperar a vez, ou esperar o momento que dê pra fazer" (M5-30m); "Porque eu sempre tô com os dois. Então, é um pouco mais difícil, porque ele [segundo filho] é menor e ele faz as bagunças. Então, eu nunca tenho como ficar só com ela [primogênita]. Antes era só com ela. Essa coisa muda bastante. Que não é só ela, tem o F. [segundo filho] junto" (M3-36m).

Na busca por não concentrar sua atenção no segundo filho, tanto os pais, quanto as mães tenderam a apresentar níveis elevados de envolvimento com o primogênito, o qual veio a receber, na maioria dos casos, mais atenção que o segundo filho: "Acho que a gente dá bem mais atenção pra ela [primogênita] agora do que quando a gente tinha ela sozinha. Acho que tá mais frisada a atenção agora. Até porque a pequenininha [segunda filha] não precisa de tanta atenção, quer dizer, precisa de atenção, mas não tanto quanto a $E$. [primogênita]. É que a idade que ela tá agora ela precisa de atenção porque ela já entende. A pequeninha não entende, precisa de carinho, mas não tanto quanto ela" (M8-18m); "Eu [pai] sentia que o F. [primogênito], em muitos momentos, ficava mais de lado. Ela [mãe] tinha que dar mais atenção pra $o$ I. [segundo filho], porque ele não entende tantas coisas. E ela já entende tudo, e solicita muito. A gente não queria que ela ficasse com essa sensação de estar de lado, então nós acabamos dando muita atenção pra ela. Ela absorve mais a gente agora" (P2-30m); "Sempre quando ela [segundo filho] tá dormindo, tá chorando, ele [primogênito] vem e pede colo. Eu largo ela [segundo filho] pra pegar ele porque ele entende mais que ela, né? Sempre que ela tá dormindo eu tô com ele brincando. Eu tento dar mais atenção pra ele. Sempre atenção pra ele" (M4-18m).

Além de perceber que o primogênito teria uma melhor compreensão da situação e, portanto, maior necessidade de atenção, os genitores justificaram este comportamento por perceberem um aumento na demanda de atenção por parte do próprio primogênito: "Eu não sei te dizer se ela [primogênita] não requisita, não absorve mais hoje do que há um ano e meio atrás. Hoje, com a presença do $F$. [segundo filho], a impressão que dá é que ela solicita mais pra competir" (P2-30m); "Chamava atenção na hora de chorar, quando eu dava mamá pra ele [segundo filho] $e$ ela [primogênita] também queria. Um dia ele [segundo filho] tava chorando, e ela disse: 'Larga o nenê no chão'," (M5-30m); “A gente cuida muito pra não deixar ele [primogênito] de lado. Nem ele nem o $V$. [segundo filho]. Porque são dois, aí quando tu vê tu dá mais atenção pra um, a gente tá sempre tentando moderar, dar atenção pra um e pro outro no mesmo nível. Até porque o L. [primogênito] é maiorzinho, o L. tá sempre na tua volta, o V. [segundo filho] é um bebê, aí tá sempre quietinho. Aí tu brinca com ele ou tu pega ele, se tu não for ali brincar com ele, ele não vem brincar contigo. $O \mathrm{~L}$. [primogênito] tá sempre na volta. Aí o L. tem ganhado mais atenção" (P7-24m).

Neste contexto, as mães relataram sentirem-se sobrecarregadas e, conseqüentemente, menos pacientes e disponíveis ao primogênito após o nascimento do segundo filho: "Eu me estressava um monte. Eu não sei se era porque eu não dormia de noite por causa dela [segundo filho]. Até hoje eu dou mamá no peito. Aí eu não tinha muita paciência com ele [primogênito]. [...] Quando era só o A. [primogênito], eu tinha mais paciência. Agora que a $S$. [segundo filho] nasceu, com os dois eu fico meio zonza. Eu poderia ser mais calma, não ser tão nervosa” (M4-36m); "Eu trabalho sozinha, fica difícil daí... Como eu fico muito cansada, às vezes eu não tenho tempo para brincar com ela [primogênita]. Então, às vezes, eu até perco a minha paciência. Ela vem me chamar para brincar com ela no chão da sala, senta, bate no tapete para eu brincar com ela e eu não tenho tempo porque eu tô também naquela correria" (M8-24m); ao mesmo tempo em que o primogênito é apontado como mais difícil e distante da mãe: "No começo ele [primogênito] não vinha mais comigo porque eu ficava mais com ela [segundo filho]. Aí nem encostar nele [primogênito] eu podia. Ele ficava ansioso. Ele não deixava eu pegar ele no colo, encostar nele. Ele ficava brabo se eu encostava nele. A gente via que era bem ciúmes mesmo" (M4-18m); "Quando eu vim do Hospital com o $V$. [segundo filho], ele [primogênito] tava no portão me esperando, ele olhou pra minha cara assim, olhou pro $V$. [segundo filho]. Ele chamava a vó dele de 'mãe'. Eu dizia: 'Vem com a mamãe'; e ele dizia: 'Não, mamãe é a vovó.' Ele não vinha comigo” (M7-24m). 
Frente a estas alterações, uma mãe demonstrou claramente seu sofrimento pelo impacto do nascimento do segundo filho sobre o primogênito e sobre a relação estabelecida com ele: "Quando a gente tava vindo pra casa no dia da alta do hospital, eu fiquei super magoada quando eu vi a $E$. [primogênita] com aquele rostinho, sabe, me deu vontade de pegar e apertar ela" (M8-18m); "Eu tinha medo de não saber lidar. Conforme foi passando os dias eu fui me sentindo melhor. Eu não consegui expressar minha felicidade quando eu tava com esse medo, mas eu não sabia que medo era, eи acho que теи medo maior era de estar no lugar da $E$. [primogênita] e sentindo o que a E. tava sentindo" (M8-18m).

Paralelamente às dificuldades enfrentadas na relação mãe-primogênito, as mães apontaram uma maior aproximação entre o primogênito e o pai no período posterior ao nascimento do segundo filho: "Mas a opção dele [primogênito], ultimamente, tem sido mais pelo pai em função de eu tá com a $F$. [segundo filho] pequena e por tá toda hora envolvida com ela, função de mamar e tudo. Então ele já tem a preferência dele pelo pai bem estabelecida. E aí ele diz: 'Eu quero men pai'," (M6-36m); "Acho que ela [primogênita] ficou mais tempo com o L. [companheiro] agora que eles tão de férias. Eu tava quase sempre dentro do hospital e o L. ficava sempre com ela. [...] Eu acho que ele [companheiro] tá mais envolvido com ela [primogênita] agora, e ela também, mais do que antes. [...] Até teve uma fase que ela nem queria saber de mim, era só ele, para dar comida, para dar banho, pra dormir, tinha que ser ele" (M8-18m); o que foi percebido como favorecendo a adaptação do primogênito às mudanças no seu relacionamento com a mãe: "E ela [primogênita] se vinculou muito mais a ele [companheiro], bastante. Naturalmente, pra ela parecia que pelo menos não seria tão sofrido de me deixar mais com ele [segundo filho]" (M5-30m).

\section{Discussão}

Como pode ser visto nos relatos das mães e pais do presente estudo, o nascimento do segundo filho tende a trazer importantes implicações para a dinâmica das relações familiares. Os participantes destacaram várias mudanças nos papéis de cada membro da família após o nascimento do segundo filho, em cada uma das categorias investigadas, a saber, a rede de apoio, a relação conjugal, o comportamento do primogênito e a relação genitores-primogênito.

No que se refere às mudanças na rede de apoio, tanto a família extensa quanto o companheiro apareceram como figuras de destaque na nova dinâmica familiar, seguidos da escola de educação infantil ou creche do primogênito. Isto corrobora os achados de Dessen e Braz (2000), que indicaram que, no período do nascimento dos filhos, os familiares foram considerados a principal fonte de apoio. Contudo, enquanto que o estudo referido apontou profissionais e instituições de saúde como fontes secundárias de apoio aos genitores, sem menção às instituições de ensino, no presente estudo estas apresentaram-se como fundamentais no momento do nascimento do segundo filho. Conforme o relato dos genitores, as escolas ou creches tiveram sua importância vinculada especialmente ao cuidado do filho mais velho. Embora mu- danças como a entrada na escola não sejam aconselhadas em momentos de transição como este, uma vez que poderia constituir-se em uma fonte de tensão extra ao primogênito que precisa lidar com o nascimento do irmão (Trause \& Irvin, 1992), diversos genitores indicaram a necessidade de colocar o filho mais velho na escola para que pudessem dar conta das tarefas domésticas, do trabalho e do cuidado do bebê. Os genitores buscavam na escola tanto uma forma de poder cuidar dos dois filhos e dar conta do trabalho, como uma maneira de envolver o primogênito em outras atividades para que não sofresse tanto com o nascimento do irmão.

Dentre as figuras de apoio familiar, a avó materna ocupou um lugar de destaque no relato das mães do presente estudo. A este respeito, segundo Levitt e cols. (1986), o relacionamento da mãe com sua própria mãe seria especialmente significativo para as mães secundíparas, quando comparadas com as primíparas. Deste modo, a avó materna passaria a desempenhar um papel de importância ainda maior no momento do nascimento do segundo filho, o que poderia estar relacionado à necessidade de maior auxílio no cuidado de dois filhos.

Quanto à relação conjugal, a principal mudança mencionada pelos participantes do presente estudo referiu-se ao afastamento do casal após o nascimento do segundo filho, confirmando a tendência de se reforçarem os papéis parentais em detrimento dos papéis conjugais neste período (Bourguignon \& cols., 1980). Tanto as mães quanto os pais foram coerentes ao destacar a necessidade de um maior investimento de energias no cuidado dos filhos, percebendo este momento como um período de adaptação e mudança de foco. Frente a isso, a maioria dos casais apontou dificuldades em resgatar o tempo e o espaço da intimidade conjugal, o que acabava por caracterizar o relacionamento do casal como mais difícil neste período. Como assinalou uma das mães, há muito tempo que o casal não saia sozinho. Embora esta possa ser uma situação muito particular, vários outros genitores indicaram uma grande limitação nos momentos íntimos do casal. Contudo, houve a exceção de um casal que se revelou mais próximo após o nascimento do segundo filho. De qualquer modo, destaca-se a congruência das falas dos homens e das mulheres e a percepção de que o companheirismo é fundamental neste momento, de modo que o casal possa funcionar como uma equipe em que cada um faz sua parte para que a família se adapte a este momento de maiores exigências. Neste contexto, o apoio recebido do cônjuge quanto às funções parentais poderia estar contrabalançando as dificuldades conjugais encontradas, já que, conforme Levitt e cols. (1986), o bemestar materno no período pós-parto estaria relacionado a três fatores principais: a satisfação conjugal, a satisfação da mãe com o apoio recebido do companheiro no cuidado aos filhos e as dificuldades vividas com os filhos.

No que tange às mudanças nos comportamentos do primogênito, todas as mães relataram que isto foi verificado em diversas áreas com o aparecimento de sintomas físicos (como febre e alergia), retrocessos na linguagem, retrocessos na alimentação, propensão ao choro, aumento de birra e manifestações de agressividade. Estes dados são coerentes com os achados de Dunn e Kendrick (1986), que apontaram que o nascimento do segundo filho teria um impacto marcante sobre o primogênito, demonstrado por meio de mudanças no seu 


\section{A. Piccinini e cols}

comportamento. As autoras ressaltaram que tais alterações estariam intimamente associadas às mudanças percebidas pelo primogênito em seu contexto familiar, de modo especial, na relação desfrutada com os genitores. Chama atenção que as alterações percebidas pelas mães chegaram até a um nível físico, com o aparecimento de febre e mesmo uma alergia em um dos primogênitos, no dia do parto. Quadros como este, que exigiu a busca por atendimento médico, demonstram que a ansiedade vivida pelo primogênito com relação ao nascimento do irmão pode ultrapassar níveis controláveis, sendo vivida através de uma desorganização de sua saúde global. Além disso, destaca-se que todas as mães associaram estas mudanças nos comportamentos do primogênito ao nascimento do irmão, reconhecendo o impacto deste na vida das crianças.

Ainda no tocante aos comportamentos do primogênito, pode-se apontar a pouca idade das crianças investigadas como favorecendo maiores dificuldades. Conforme Kramer e Ramsburg (2002), crianças menores - 1 a 6 anos - tendem a reagir mais negativamente ao nascimento de um irmão do que crianças que já se encontram na terceira infância - 6 a 12 anos. Segundo os autores, crianças relativamente mais velhas possuem habilidades sociais e cognitivas mais bem desenvolvidas que lhes permitiriam entender e tolerar melhor algumas mudanças familiares neste momento de transição.

Quanto ao relacionamento genitores-primogênito, a principal mudança destacada pelas mães e pais se referiu à redistribuição da atenção entre os filhos. Muitas mães e alguns pais destacaram a busca por manter níveis elevados de envolvimento com o primogênito, inclusive fornecendo mais atenção a este do que ao segundo filho. Por um lado, isso se deveu, segundo os genitores, a um aumento na demanda de atenção do primogênito e, por outro, à percepção parental de que o filho mais velho estaria vivendo um período difícil e, por compreender melhor a situação, necessitaria mais atenção que o bebê. Chama atenção a sensibilidade dos pais para tentar equacionar as demandas do primogênito e do segundo filho, buscando atender a ambos de um modo adequado, tanto afetivamente como em termos de cuidados e brincadeiras. Obviamente, para que pudessem manter níveis elevados de atenção ao primogênito, ao mesmo tempo em que tinham de cuidar do recém-nascido, foi necessário algum desinvestimento emocional em outras relações e atividades familiares. Conforme mencionado anteriormente, parece que esta opção recaiu sobre a conjugalidade, com o conseqüente comprometimento da qualidade do relacionamento do casal, que ficou, pelo menos temporariamente, em segundo plano.

Cabe ressaltar que as mesmas mães que propunham dedicar sua atenção ao primogênito após o nascimento do irmão, afirmaram sentirem-se sobrecarregadas e, conseqüentemente, menos disponíveis e tolerantes com ele neste período. Contudo, esta aparente contradição encontra respaldo na literatura, que indica que por um lado haveria uma diminuição na freqüência e na qualidade afetiva das interações mãe-primogênito (Dunn \& Kendrick, 1980, 1986; Field \& Reite, 1984; Stewart \& cols., 1987) e, por outro, uma maior disponibilidade materna e um aumento na provisão de atividades de estímulo cognitivo ao primo- gênito, o que incluiria encorajamento de realizações da criança, estimulação do desenvolvimento da linguagem e oferta de uma variedade de experiências de aprendizado (Kowaleski-Jones \& Dunifon, 2004). Pode-se conjecturar, então, que o declínio da interação mãe-primogênito poderia ocorrer mais na sua dimensão afetiva do que na freqüência da interação mãe-primogênito em si.

A grande sensibilidade materna às mudanças comportamentais do primogênito, e as mudanças na sua relação com este parecem refletir-se especialmente na preocupação da mãe com o primogênito no momento da chegada do segundo filho. Conforme Walz e Rich (1983), o nascimento do segundo filho pode trazer sofrimento às mães por perceberem a vulnerabilidade do primogênito, o qual necessitaria de cuidados especiais para se adaptar, assim como por preverem um rompimento na relação diádica íntima e exclusiva desfrutada, até então, com este. Deste modo, percebe-se que não apenas o primogênito estaria vivendo um momento delicado, mas também para a mãe o nascimento do segundo filho e a mudança em seu relacionamento com o primogênito seriam fonte de grande preocupação e sofrimento. De forma muito empática com os primogênitos, as mães do presente estudo demonstraram sofrer ao perceber as dificuldades das crianças em lidar com a chegada do bebê. Pequenos sinais de descontentamento, como o "rostinho" da filha quando a mãe chegou em casa com o bebê, foram suficientes para preocupar a mãe. Neste contexto, uma mãe relatou inclusive não conseguir sentir alegria com a chegada do bebê, devido ao sofrimento do primogênito, o que ela descreveu como medo de estar em seu lugar e sofrer o que ela estaria sofrendo.

Frente às alterações na relação mãe-primogênito, o aumento no envolvimento paterno parece indicar que as famílias estariam buscando novas estratégias de distribuição da atenção parental, tema bastante enfatizado pelos participantes. Em relação a isso, Dessen (1997) e Tilmans-Ostyn e Meynckens-Fourez (2000) sugeriram que o reequilíbrio na distribuição da atenção entre os filhos seria uma das principais tarefas da família na adaptação ao nascimento do segundo filho. Frente à grande alteração na disponibilidade da mãe, o pai tende a se ajustar às necessidades da família e a aumentar sua contribuição relativa, mantendo níveis estáveis de interação com o primogênito (Stewart \& cols., 1987), ou ainda, passando a iniciar mais interações com este (Dessen \& Mettel, 1984; Kreppner, 1988). Isso parece refletir uma distribuição típica dos cuidados dos filhos entre os genitores, em que o pai desempenha um papel secundário com relação às crianças pequenas, mas pode aliviar a tarefa da mãe em relação aos filhos mais velhos. Conforme os relatos das participantes do presente estudo, enquanto a mãe precisava envolver-se intensamente com as tarefas de cuidado do recém-nascido, o pai pôde suprir as necessidades de atenção do primogênito, tornando-se, inclusive, o preferido do primogênito em alguns casos. Esta redistribuição da atenção entre os genitores é fundamental quando se considera que, como apontado pelos genitores, tanto a mãe estava mais cansada e indisposta fisicamente, quanto o primogênito estava mais difícil e apresentando mais comportamentos de enfrentamento com a mãe.

Além disso, Dunn e Kendrick (1986) revelaram que nos casos em que o pai é capaz de cuidar e distrair o primogê- 
nito de modo eficaz, este parece sentir-se menos aborrecido com o envolvimento da mãe com o bebê. Com isso, o pai proporcionaria maior continuidade na vida emocional do primogênito no período pós-parto (Trause \& Irvin, 1992). A este respeito, uma mãe referiu que não seria tão difícil para o primogênito abdicar de sua atenção, uma vez que poderia contar mais com o pai.

Em síntese, o nascimento do segundo filho afeta de modo global a dinâmica das relações familiares. Segundo o relato dos genitores, nenhuma das categorias de análise proposta teve maior destaque que as demais, indicando que, mais que algum aspecto em particular ou alguma relação específica, é a família como um todo que passa por mudanças neste período. Entretanto, em função do número de participantes do presente estudo, pode-se esperar que outras famílias, vivendo em diferentes contextos, apresentem formas particulares de adaptação ao nascimento do segundo filho. Isso reflete a necessidade de retomada das investigações a respeito deste tema, que é fundamental para a compreensão das relações familiares.

Os resultados do presente estudo também revelam uma diversidade de modos pelos quais os genitores e os primogênitos podem lidar com o nascimento do segundo filho. Apesar dos poucos casos investigados, encontrou-se uma riqueza de situações que retratam o esforço de cada membro das famílias para lidar com as ambigüidades desta situação em que, ao mesmo tempo em que o segundo filho é bem vindo e celebrado, ele altera uma dinâmica familiar relativamente estável envolvendo a tríade pai-mãe-primogênito. Embora as alterações relatadas com o nascimento do segundo filho possam ter sido acompanhadas de certa ansiedade e instabilidade, os relatos denotam a capacidade adaptativa dos membros destas famílias e a força dos sistemas familiares estudados. Retomando Minuchin (1982), a força de um sistema reside em sua capacidade de mobilizar padrões transacionais alternativos quando em momentos de reestruturação familiar. Obviamente, trata-se de famílias que já vinham sendo acompanhadas desde a gestação, como participantes do estudo longitudinal $\mathrm{e}$, por isto mesmo, provavelmente bastante envolvidas com a parentalidade e, eventualmente, motivadas para terem mais de um filho. Deste modo, os achados poderiam ser bem mais complexos e problemáticos caso o segundo filho proviesse de uma situação em que o desejo pela nova gravidez não estivesse presente ou as relações familiares fossem bastante conflituosas ou, ainda, quando as condições socioeconômicas não fossem adequadas. Destaca-se, assim, a necessidade de estudos futuros investigarem tal transição normativa no contexto de famílias de diferentes classes sociais, possibilitando uma compreensão mais aprofundada deste período. Tal contribuição parece valiosa tanto para o cenário da pesquisa nacional, quanto internacional.

Apesar da relevância do nascimento do segundo filho para a dinâmica familiar, como pôde ser visto, são ainda muito escassas as pesquisas que retratam esta realidade. $\mathrm{Na}$ literatura existente sobressaem estudos da década de 1980, com uma retomada modesta nos anos 1990 e 2000. Além disso, os estudos são predominantemente internacionais. De qualquer modo, o nascimento do segundo, ou também do terceiro ou quarto, merece atenção por parte dos profissionais de saúde mental, pois, assim como no caso do primeiro filho, trata-se sempre de um momento complexo de transição, em que a falta de condições adequadas pode afetar intensamente não só a parentalidade, mas também a conjugalidade e, particularmente as próprias crianças, com implicações para todos os subsistemas: conjugal, parental e fraterno. Com isso, é importante que se aumente o número de estudos empíricos que auxiliem na fundamentação de programas de apoio e educação a familiares no período do nascimento de filhos.

\section{Referências}

Bardin, L. (1977). Análise de Conteúdo (L. Reto \& A. Pinheiro, Trad.). São Paulo: Edições 70/Livraria Martins Fontes.

Baydar, N., Greek, A. \& Brooks-Gunn, J. (1997). A longitudinal study of the effects of the birth of a sibling during the first six years of life. Journal of Marriage and the Family, 59, 939-956.

Belsky, J. (1981). Early human experience: A family perspective. Developmental Psychology, 17, 3-23.

Bourguignon, O., Alary, A., Butat, M., Cessans, A., Coloignier, R., Duvillie-Moustacchi, R., Hirsch-Pelissier, A., JaurandBulvestre, A., Ouassini, M., Nzeyimana, N., Salmon, N. \& Samama, C. (1980). Changes in the family with the arrival of a second child. Bulletin de Psychologie, 34, 289-304.

Brazelton, B. \& Sparrow, J. (2003). Três a seis anos: Momentos decisivos do desenvolvimento infantil (C. Monteiro, Trad.) Porto Alegre: Artes Médicas.

Carter, B. \& McGoldrick, M. (Orgs.) (2001). As mudanças no ciclo de vida familiar: Uma estrutura para a terapia familiar ( $2^{\text {a }}$. ed., M. V. Veronese, Trad.). Porto Alegre: Artes Médicas (Trabalho original publicado em 1989)

Dessen, M. (1997). Desenvolvimento familiar: Transição de um sistema triádico para poliádrico. Temas em Psicologia, 3, 51-61.

Dessen, M. \& Braz, M. (2000). Rede social de apoio durante transições familiares decorrentes do nascimento de filhos. Psicologia: Teoria e Pesquisa, 16, 221-231.

Dessen, M. \& Mettel, T. (1984). Interação pais-primogênito quando da chegada de uma segunda criança na família: Um estudo de caso. Psicologia, 10, 27-39.

Dunn, J. \& Kendrick, C. (1980). The arrival of a sibling: Changes in patterns of interaction between mother and firs-born child. Journal of Child Psychology and Psychiatry, 21, 119-132.

Dunn, J. \& Kendrick, C. (1986). Hermanos y hermanas: Amor, envidia y compreensión (C. Barrio, B. Barrio \& B. Slobodziaanek, Trad.). Madrid: Alianza Editorial.

Feiring, C \& Lewis, M. (1978). The child as a member of family system. Behavioral Science, 23, 225-233.

Field, T. \& Reite, M. (1984). Children's responses to separation from mother during the birth of another child. Child Development, 55, 1308-1316.

Gottlieb, L. \& Baillies, J. (1995). Firstborns' behaviors during a mother's second pregnancy. Nursing Research, 44, 356-362.

Grupo de Interação Social, Desenvolvimento e Psicopatologia/Núcleo de Infância e Família - GIDEP/UFRGS/CNPq (1998). Entrevista de Dados Demográficos. Instrumento não-publicado. Instituto de Psicologia. Universidade Federal do Rio Grande do Sul.

Grupo de Interação Social, Desenvolvimento e Psicopatologia/ Núcleo de Infância e Família - GIDEP/UFRGS/CNPq (2000a). Entrevista com o Casal com Bebê de 18 meses. Instrumento não-publicado. Instituto de Psicologia. Universidade Federal do Rio Grande do Sul. 


\section{A. Piccinini e cols}

Grupo de Interação Social, Desenvolvimento e Psicopatologia/Núcleo de Infância e Família-GIDEP/UFRGS/CNPq (2000b). Entrevista sobre Práticas Educativas Parentais. Instrumento não-publicado. Instituto de Psicologia. Universidade Federal do Rio Grande do Sul.

Grupo de Interação Social, Desenvolvimento e Psicopatologia/Núcleo de Infância e Família - GIDEP/UFRGS/CNPq (2000c). Entrevista sobre a Experiência da Maternidade e o Desenvolvimento da Criança. Instrumento não-publicado. Instituto de Psicologia. Universidade Federal do Rio Grande do Sul.

Grupo de Interação Social, Desenvolvimento e Psicopatologia/Núcleo de Infância e Família - GIDEP/UFRGS/CNPq (2000d). Entrevista sobre a Experiência da Paternidade e o Desenvolvimento da Criança. Instrumento não-publicado. Instituto de Psicologia. Universidade Federal do Rio Grande do Sul.

Grupo de Interação Social, Desenvolvimento e Psicopatologia/Núcleo de Infância e Família - GIDEP/UFRGS/CNPq (2001). Entrevista com os pais aos 30 e 36 meses. Instrumento não-publicado. Instituto de Psicologia. Universidade Federal do Rio Grande do Sul.

Hollignshead, A. B. (1975). Four factor index of social status. Unpublished manuscript. Department of Sociology. Yale University.

Kramer, L. \& Ramsburg, D. (2002). Advice given to parents on welcoming a second child: A critical review. Family Relations, 51, 2-14.

Kowaleski-Jones, L. \& Dunifon, R. (2004). Childrens's home environment: Understanding the role of family structure changes. Journal of Family Issues, 25, 3-28.

Kreppner, K. (1988). Changes in parent-child relationships with the birth of the second child. Em R. Palkovitz \& M. Sussman (Orgs.), Transitions to Parenthood (pp. 157-181). New York: The Haworth Press.

Kreppner, K., Paulsen, S. \& Schuetze, Y. (1982). Infant and family development: From triads to tetrads. Human Development, 25, 373-391.

Laville, C. \& Dionne, J. (1999). A construção do saber: Manual de metodologia de pesquisa em ciências humanas. Porto Alegre: Artes Médicas.
Levitt, M., Weber, R. \& Clark, M. (1986). Social network relationships as sources of maternal support and well-being. Developmental Psychology, 22, 310-316.

Minuchin, P. (1985). Families and individual development: Provocations from the field of family therapy. Child Development, 56, 289-302.

Minuchin, S. (1982). Famílias: Funcionamento e tratamento (J. A. Cunha, Trad.). Porto Alegre: Artes Médicas.

Pereira, C. \& Piccinini, C. (no prelo). O impacto da gestação do segundo filho na dinâmica familiar: aspectos teóricos e empíricos. Estudos de Psicologia.

Piccinini, C. A., Tudge, J. R., Lopes, R. C. \& Sperb, T. (1998). Projeto Longitudinal de Porto Alegre: Da Gestação à Escola. Projeto não-publicado, Curso de Pós-Graduação em Psicologia do Desenvolvimento, Universidade Federal do Rio Grande do Sul. Porto Alegre, RS.

Silveira, L. (2002) O relacionamento fraterno e suas características ao longo do ciclo vital da família. Em A. Wagner (Org.), Família em cena: Tramas, dramas e transformações (pp. 93-112). Petrópolis: Vozes.

Stake, R. E. (1994). Case Studies. Em N. Denzin \& Y. Lincoln (Orgs.), Handbook of qualitative research (pp. 236-247). Londres: Sage.

Stewart, R. B., Mobley, L. A., Van-Tuyl, S. \& Salvador, M. A. (1987). The firstborn's adjustment to the birth of a sibling: A longitudinal assessment. Child Development, 58, 341-355.

Tilmans-Ostyn, E. \& Meynckens-Fourez, M. (Orgs.) (2000). Os recursos da fratria (C.A. Molina-Loza \& A.M. Prates, Trad.). Belo Horizonte: Artesã.

Trause, M. \& Irvin, N. (1992). Atendimento aos irmãos. Em M. Klaus \& J. Kennell (Orgs.), Pais/Bebê: A formação do apego (pp.129-148). Porto Alegre: Artes Médicas.

Walz, B. \& Rich, O. (1983). Maternal tasks of taking-on a second child in the postpartum period. Maternal-Child Nursing Journal, $12,185-216$.

Recebido em 21.06.2006

Primeira decisão editorial em 28.08.2006

Versão final em 02.05.2007

Aceito em 15.06.2007 